\title{
BMK Blood Test Result as Evaluation of Bisphosphonates Used for the Treatment of Osteoporosis
}

\author{
Emeritus Sek Aksaranugraha* \\ Director, Thai Red Cross Rehabilitation Center, Samut Prakarn, Thailand \\ ${ }^{\star}$ Corresponding author: Emeritus Sek Aksaranugraha, Director, Thai Red Cross Rehabilitation Center, Samut Prakarn, Thailand
}

Received: February 25, 2021; Accepted: March 03, 2021; Published: March 22, 2021

There has been long use of Bisphosphonates for bone antiresorption; for example,

Alendronate $10 \mathrm{mg}: 1$ tablet/day

Alendronate $70 \mathrm{mg}: 1$ tablet/week

Risedronate $5 \mathrm{mg}: 1$ tablet/day

Risedronate 35 mg: 1 tablet/week

Risedronate $150 \mathrm{mg}: 1$ tablet/month

Ibandronate $150 \mathrm{mg}: 1$ tablet/month

However, effectiveness of the recommended dosage and appropriate length of time have never been evaluated. After blood test for Biological Bone Marker, studies have been gathered for more than 10 years or since 2005-2017, and surprisingly, remarkable results have been found out.

First of all, BMK blood test must be correct throughout its process, for reliable and accurate results [1].

1. No food is allowed for patients from $8 \mathrm{pm}$ to $8 \mathrm{am}$ (12 hrs)

2. Blood sample is taken between 8 am to 9 am only (normal values specified by Prof. Dr. Narong B)

3. Blood Test by the Laboratory needs to be done immediately as result value varies by time.

4. Solution used for running the BMK blood test must be calibrated every morning.

This report covers evaluation on bone resorting value which is CTx or Beta Cross Laps only. Normal value specified by Prof. Dr. Narong B. is 0.31 for female [2].

If CTx or Beta Cross laps as measured $=0.31$ for female, there will be $100 \%$ bone resorption, as normal, for female. If CTx is more than $100 \%$ bone resorption is faster or higher than normal. If CTx is less than $100 \%$, bone resorption is slower or lesser than normal.

Example CTx value of a patient $=0.45$

CTx $0.31=100 \%$
If $0.45=\underline{100 \times 0.45}=145 \% 45 \%$ more than normal bone resorption 0.31

Or

CTx value of a patient $=0.21$

CTx $0.31=100 \%$

If $0.21=\underline{100 \times 0.21}=67.7 \% 32.3 \%$ less than normal bone resorption 0.31

This report covers 708 patients on $5^{\text {th }}$ floor, King Bhumibhol Building, Chulalongkorn Hospital from 2005-2017 having been controlled the dose of bisphosphonates by BMK Blood Test, but only 480 patients or $66.8 \%$ having been given Bisphosphonate.

196 patients have had Ibandronate $150 \mathrm{mg}$ and 27 ones have taken it several years before treatment $=223$ patients

148 patients have had Alendronate $70 \mathrm{mg}$ and 16 ones have taken it several years before treatment $=164$ patients

26 patients have had Alendronate $10 \mathrm{mg}$ and 12 ones have taken it several years before treatment $=38$ patients

15 patients have had Risedronate $35 \mathrm{mg}$ and 5 ones have taken it several years before treatment $=20$ patients

12 patients have had Risedronate $150 \mathrm{mg}$ and one has taken it several years before treatment $=13$ patients

The result has turn out, astonishingly, opponent for patients, costing a lot as well even though both doctors and patients have been confident treatment was in the right direction. Consequently, there is in depth analysis of 480 patients using Bisphosphonates as shown in the followings.

Result of one month administration of Bisphosphonates [3].

Comments One month course of all bisphosphonates have so effective:

- Ibandronate $150 \mathrm{mg}$ can reduce CTx from $181.8 \%$ to $49.8 \%$

- Alendronate $70 \mathrm{mg}$ can reduce CTx from $140.3 \%$ to $31.9 \%$ 
- Alendronate $10 \mathrm{mg}$ can reduce CTx from $157.2 \%$ to $37.1 \%$

- Risedronate $35 \mathrm{mg}$ can reduce CTx from $158 \%$ to $62.5 \%$

\section{- Risedronate $150 \mathrm{mg}$ can reduce CTx from $154 \%$ to $47.4 \%$}

If there had not been BMK blood test and dosage had been given to patients continuously, CTx would have been reduced to the point that the bone will have no bone resorption. So, there would have been only old bone cells, prone to degeneration and necrosis. Only light or minor injury, bones are easily broken. For example, when a tooth is extracted, mandible is also broken.

Basically, there are differences of effective period of dosage used for patients. So, each patients is required to have BMK blood test once a month after being treated with Bisphosphonate, and will continue until effectiveness period for 1 tablet is evaluated (CTx 70-100\%)

For example, Mr. A has 1 tablet of Ibandronate monthly as instructed by the pharmaceutical manufacturer. In fact, he needs only 1 tablet per 3 months which is accurate and costs him 3 times less. This result shows Bone resorption is between $70-100 \%$ in control forever.

When discontinued bisphosphonates, it will take months to resume bone resorption until the acceptable safe level which means CTx $70 \%$ up to $100 \%$ :

- Ibandronate $150 \mathrm{mg}$ : average of 4.1 months resuming acceptable rate of bone resorption

- Alendronate $70 \mathrm{mg}$ : average of 3.5 months resuming acceptable rate of bone resorption

- Alendronate $10 \mathrm{mg}$ : average of 6 months resuming acceptable rate of bone resorption

- Risedronate $35 \mathrm{mg}$ : average of 4 months resuming acceptable rate of bone resorption

- Risedronate $150 \mathrm{mg}$ : average of 2.8 months resuming acceptable rate of bone resorption

It shows that there are inconsistent results for each bisphosphonate, no matter how much dosage given to each patient in one month, even the same medicine. CTx after one month of treatment shows in consistent effectiveness deepening on each patient condition such as genetic background, food, illness, other treatments with herbs or jinseng and fruits. Those can give different CTx results. Initially, BMK blood test is needed once a month, later on once in 3 month or 6 months. However, it should not wait too long. Eventually, once in 6 month or once a year is an appropriate. When change is found, root cause should be analyzed to help CTx to resume.

Moreover, there are 1 or 2 dosages for each medicine. Adjustment for early patient seems to be difficult; for example, Alendronate should be adjusted from $70 \mathrm{mg}$ to $10 \mathrm{mg}$, but there isn't such a small dosage sold. So, length of time of effectiveness for one tablet needs to be evaluated so that CTx will be in $70-100 \%$. In the future if different dosages are produced, it will help patients to resume their CTx to 70$100 \%$ within days instead of months, giving not so effective result; too long of low CTx.
It was found that one month of drugs administration will last longer than recommendation.

- Ibandronate $150 \mathrm{mg}: 1$ tablet has an average of 4.1 months in effectiveness.

- Alendronate $70 \mathrm{mg}: 4$ tablets has an average of 3.5 months in effectiveness.

- Alendronate $10 \mathrm{mg}: 30$ tablets has an average of 6 months in effectiveness.

- Risedronate $35 \mathrm{mg}: 4$ tablets has an average of 4 months in effectiveness.

- Risedronate 150 mg: 1 tablet has an average of 2.8 months in effectiveness.

No matter which medicines given in a month according to the manufacture, similar results will come out. When stopping the use of those medicines, it will take 3-4 months to resume CTx to $70-100 \%$. The results for all medicines are similar. Effectiveness length of time of medicine prescription for each patient can be different depending on patient's conditions whether to resist or accept dosage, their illness conditions, their other treatments, as well as fruits they eat. We can see that all mentions including some herbs or supplements will affect CTx, increasing $100+\%$ of which data has been collected.

Average length of time of CTx after long administration of bisphosphonate resume to normal for each medicine :

- Ibandronate $150 \mathrm{mg}: 27$ patients had an average of $25.18 \%$ CTx only, waiting for 13.3 months to resume to normal.

- Alendronate $70 \mathrm{mg}: 27$ patients had an average of $21.2 \%$ CTx only, waiting for 16.8 months to resume to normal.

- Alendronate $10 \mathrm{mg}: 27$ patients had an average of $25 \%$ CTx only, waiting for 13.3 months to resume to normal.

- Risedronate 35 mg: 6 patients had an average of $10.8 \%$ CTx only, waiting for 10.1 months to resume to normal.

- Risedronate $150 \mathrm{mg}: 2$ patients had $0 \%$ of CTx without resuming.

There are cases that patients having Bisphosphonate for years, but from BMK blood test, CTx is too low or 0\% showing no Bone resorption at all: So, Bisphosphonate given to patients for years can turn out disadvantages due to low rate of bone resorption and high cost of treatment until they require long time to resume to normal. Especially for those 2 patients who had no recovery at all.

It is important to control CTx value in $70-100 \%$ besides what was mentioned in 1, Bone life cycle range is considered safe. If CTx is higher than $100 \%$, bone resorption will be more than normal, or bone age will be shorter. Micro fracture can easily happen. It can remarkably decrease bone structure, causing bone fractures more easily. Therefore, CTx or Bone resorting needs to be $70-100 \%$, and if this is controlled, a little longer bone life cycle means Micro fracture prevention. 


\section{Conclusion}

BMK blood test is required to evaluate if bone antiresorptive medicine used for osteoporosis treatment is appropriate for patients; dosage amount, tablet effectiveness in months, weeks or days, and adjustment must be accurate and patient can save a lot of money.

\section{References}

1. Bernardi D, Zaninotto M, Plebani M (2004) Requirements for improving quality in the measurement of bone markers. Clin Chim Acta 346: 79-86. [crossref]

2. Bunyaratavej N, Kitimanon N, Boonthitikul S (2001) Study of the level of biochemical bone markers: NMID osteocalcin and bone resorptive marker (beta CTx) in Thai women. J Med Assoc Thai 84: S560-565. [crossref]

3. Aksaranugraha S (2011) Observation: Application and Advantages of BMK in OP by Monitoring the Dose of Antiresorption Drugs with CTx. J Med Assoc Thai 94: S 65-66. [crossref] 